\title{
Dietary vitamin a intake among Chinese adults: findings from CNTCS2015
}

\author{
Wenwen Du, Huijun Wang, Zhihong Wang, Jiguo Zhang, Chang Su, Xiaofang Jia, Ji Zhang, Hongru Jiang,
} Feifei Huang, Yifei Ouyang, Yun Wang, Li Li and Bing Zhang ${ }^{*}$ (i)

\begin{abstract}
Background: Vitamin A plays an important role in human functions, which mainly come from foods. This study aims to examine dietary vitamin A intake and major food sources of Chinese adults.

Methods: We analyzed the cross-sectional data from 12,246 adult aged 18 to 64 years old in 2015 China Nutritional Transition Cohort Study. Three consecutive 24-h dietary recalls combined with household weighing method were used to assess dietary vitamin A intake.

Results: The average dietary vitamin A intakes were $480.9 \mu \mathrm{g}$ retinol equivalents (RE) or $307.2 \mu \mathrm{g}$ retinol activity equivalents (RAE). The carotenes and retinol intake of subjects were $2084.7 \mu \mathrm{g} /$ day and $133.5 \mu \mathrm{g} /$ day, respectively. Approximately $87 \%$ of adults consumed less vitamin A than the Chinese Estimated Average Requirement (EAR), and only $6 \%$ of adults consumed more than Chinese Recommended Nutrient Intake (RNI). Chinese adults derived vitamin A mainly from plant source foods, which is supplied as carotenes (67.4\% RE or 56.4\% RAE). Dark- and light- vegetables and fruits were major contributors of carotenes (accounted for 84.2\%). The most import food sources of retinol were egg, meats and meat products, poultry, fish and milk, representing $94.7 \%$ of retinol intake. The major four contributors of total vitamin A (as both RE and RAE) were dark vegetables, egg, light vegetables, and meats and meat products. In conclusion, dietary vitamin A remains a problem for Chinese adults.
\end{abstract}

Conclusions: Public health actions are needed to increase vitamin A intake in China.

Keywords: Vitamin A, Retinol, Carotenes, China

\section{Background}

Vitamin $\mathrm{A}$ is an essential fat-soluble nutrient for eye health, immune function, embryonic development, cell differentiation and growth hormone production [1]. Low vitamin A intake may lead to blindness and increased morbidity and mortality. Vitamin A deficiency remains a major public-health issue in developing countries, especially in low-income regions, such as south Asia and sub-Saharan Africa [2]. In China, vitamin A deficiency is now considered a moderate public-health problem. On the positive side, recent studies indicate that vitamin A status has been improved in the past decade for Chinese children and pregnant women $[3,4]$.

Vitamin $\mathrm{A}$ is a generic term comprising retinol and provitamin A carotenoids $(\beta$-carotene, $\alpha$-carotene, and

\footnotetext{
* Correspondence: zhangbing@chinacdc.cn; zzhangb327@aliyun.com National Institute for Nutrition and Health, Chinese Center for Disease Control and Prevention, 29 Nanwei Rd, Beijing, China
}

$\beta$-cryptoxanthin). People obtain dietary vitamin A either as retinol from animal foods or as provitamin A carotenoids from vegetables and fruits $[5,6]$. With respect to the rentinol activity, the former equivalent of vitamin A intake is proposed by FAO/WHO (1988) as RE (retinol equivalent $)=$ retinol $+(\beta$-carotene $/ 6)+(\alpha$-carotene $/ 12)+$ ( $\beta$-cryptoxanthin/12) [7],while the present equivalent is introduced by IOM (2001) as RAE (retinol activity equivalent $)=$ retinol $+(\beta$-carotene $/ 12)+(\alpha$-carotene $/$ $24)+(\beta$-cryptoxanthin/24) $[1,8]$. Several countries have issued new dietary reference intakes (DRIs) of vitamin A as RAE, such as the United States, Canada, and Australia, where it recommended $900 \mu \mathrm{g}$ for men and $700 \mu \mathrm{g}$ for women $[1,9]$. Chinese DRIs recommended $800 \mu \mathrm{g}$ for men and $700 \mu \mathrm{g}$ for women [10].

It is still unclear whether Chinese adults eat enough to meet the recent recommended dietary intakes of vitamin A as well as its food sources at the national level. In the

(C) The Author(s). 2018 Open Access This article is distributed under the terms of the Creative Commons Attribution 4.0 International License (http://creativecommons.org/licenses/by/4.0/), which permits unrestricted use, distribution, and 
present article, we examined the dietary vitamin A status (as retinol, carotenoids, RE and RAE) and its food sources among Chinese adults aged 18 to 64 years, using data from the most recent China Nutritional Transition Cohort Study (CNTCS, 2015).

\section{Methods}

\section{CNTCS and sample}

We used data from CNTCS 2015, which was conducted by National Institute for Nutrition and Health, Chinese Center for Disease Control and Prevention. CNTCS was an amplified survey based on the China Health and Nutrition Survey (CHNS), an ongoing and longitudinal study established in 1989 by the Chinese Center for Disease Control and Prevention, and the University of North Carolina at Chapel Hill. Detailed information on the rationale and methods of CHNS can be found on the project website and published papers [11, 12]. CNTCS was designed to provide a wide range of socio-demographic characteristics, diet, health, physical activity, behaviors and environment changes in China. The original sample was collected using a multistage random cluster sampling method from representative households in eight provinces (Liaoning, Shandong, Henan, Hubei, Hunan, Jiangsu, Guizhou and Guangxi) by economic levels, geographical areas, and public resources. During the past decades, more provinces joined the study using the consistent sampling method and protocol: Heilongjiang joined in 1997, three mega cities (Beijing, Shanghai and Chongqing) joined in2011, and three more provinces (Zhejiang, Shanxi and Yunnan) joined in 2015.

All subjects gave their written informed consent before they participated in the study. The study was conducted in accordance with the Declaration of Helsinki, and the protocol was approved by the Ethics Committee of the National Institute for Nutrition and Health, China CDC (No.2015017).

The current paper analyzed data from 12,246 adults (5710 men and 6536 women), aged18 to 64 years old, who had complete dietary data on three consecutive days in 2015. The final sample came from 6018 households, residing in 361 communities from 15 provinces in China.

\section{Assessment of dietary carotenes, retinol and vitamin a (RE, RAE) intake}

Personal dietary data were collected using 24-h recalls on three consecutive days (two weekdays and one weekend day) by face-to-face interview. The trained interviewers collected detailed information of all foods and beverages consumed at home and away from home in the past $24 \mathrm{~h}$ for each individual. Household edible oil and condiments consumption were weighed during the same days and divided among household members according to their dietary energy intake levels.

Dietary carotenes and vitamin A (RE) intake were calculated using the China Food Composition Table 2009 [13]. However, carotenes was tested using chromatography in the China Food Composition Dataset, which could not distinguish the subtypes, such as $\beta$-carotene, $\alpha$-carotene, and $\beta$-cryptoxanthin. Other research showed that $\beta$-caroteneaccounts for $86 \%$ of provitamin A carotenoids intake [14]. Therefore, we used the conversion factor of $\beta$-carotene instead that of total carotenes in the calculation procedures. Retinol and vitamin A (RAE) were derived from the following simplified formulas:

$$
\begin{aligned}
& \mu \mathrm{g} \mathrm{RE}=\mu \mathrm{g} \text { retinol }+\mu \mathrm{g} \text { carotenes } / 6, \\
& \mu \mathrm{g} \mathrm{RAE}=\mu \mathrm{g} \text { retinol }+\mu \mathrm{g} \text { carotenes } / 12 .
\end{aligned}
$$

Food groups were defined according to the classification in China Food Composition Tables. Carotene was the major contributor to vitamin A intake in vegetables, which varied in different vegetable types. Thus, we defined vegetables with carotene more than $500 \mu \mathrm{g} / 100 \mathrm{~g}$ as dark vegetables, which mainly were dark green, red or orange (such as spinach, broccoli, tomato, carrot and

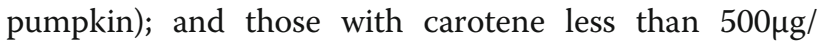
$100 \mathrm{~g}$ as light vegetables (such as eggplant, cucumber and cabbage).

\section{Socio-demographic variables}

Socio-demographic variables used in the present analysis include: age, gender, education and income level, and regions. Age (years) was categorized to 2 groups, 1849 years, and 50-64 years. Highest level of education attained was categorized to 3 groups, primary school andbelow, junior middle school and senior middle school and above. Per capita annual household income was classified into 3 groups using tertile method, low ( $1^{\text {st }}$ tertile), middle (2ndtertile), and high (3rdtertile). Ethnic groups were divided into Han, Miao, Buyi, Man, and others. To explore region disparities on vitamin A intake, we included 3 variables, region1 (urban, rural), region2 (east: Being, Liaoning, Shanghai, Jiangsu, Zhejiang and Shandong; middle: Heilongjiang, Henan, Hubei and Hunan; west: Chongqing, Guizhou, Yunnan, Shanxi and Guangxi), and region3 (north: Beijing, Liaoning, Shandong, Heilongjiang, Henan and Shanxi; south: Shanghai, Jiangsu, Zhejiang, Hubei, Hunan, Chongqing, Guizhou, Yunnan and Guangxi).

\section{Statistical methods}

In our analysis, vitamin A was expressed as both retinol equivalent (RE) and retinol activity equivalent (RAE). The present paper reported dietary carotenes, retinol, vitamin A (RE), and vitamin A (RAE) intakes (mean of 
the three days for each adult) as mean (SD) and median by age, gender, region, education, income and ethnic groups. The intake levels of vitamin A (RAE) were assessed using estimated average requirement (EAR) and recommended nutrient intake (RNI) from Chinese Dietary Reference Intakes (DRIs) 2013 [15]. The proportions of retinol to total RE and RAE, as well as the main food sources contributing to each of the vitamin A components were also determined. Non-parametric statistical methods were used for difference test by each of the stratifications. Significance level was set at $p<0.05$. All statistical analysis was conducted using SAS 9.4 (SAS Institute Inc., Cary, NC, USA).

\section{Results}

\section{Dietary intake of vitamin a among Chinese adults}

Table 1 reports the dietary intake of carotenes, retinol, and vitamin A (excluding supplements) by age, gender, region, education, income level and ethnic groups among Chinese adults. Mean total dietary intake of vitamin A was $480.9 \mu \mathrm{g}$ RE/day (male: $499.4 \mu \mathrm{g} R E /$ day; female: $464.7 \mu \mathrm{g} \mathrm{RE} /$ day) or $307.2 \mu \mathrm{g} \mathrm{RAE} /$ day (male: $321.3 \mu \mathrm{g}$ RAE/day; female: $294.8 \mu \mathrm{g}$ RAE/day), carotenes intake was $2084.7 \mu \mathrm{g} /$ day (male: $2137.7 \mu \mathrm{g} /$ day; female: $2038.4 \mu \mathrm{g} /$ day), and retinol was $133.5 \mu \mathrm{g} /$ day (male: $143.2 \mu \mathrm{g} /$ day; female: $125.0 \mu \mathrm{g} /$ day).

Higher intake of carotenes was observed in western areas vs. middle and eastern areas, in rural areas vs. urban area, in southern areas vs. northern areas, in Buyi and Miao minorities VS. other ethnic groups. Lower carotenes intake was found in low subgroup compared with middle-high groups of education and income. No significant differences of carotenes intake were detected by age and gender.

Retinol intake was significantly higher in younger adults compared to older adults, and in males compared to females. Opposite to carotenes intake, the higher intake of retinol was observed in urban areas vs. rural areas, and in eastern areas vs. middle and western areas. Adults in southern areas tended to have significant higher retinol intake than those in northern areas. Similarly, retinol intake was found to increase with education and income level. Buyi minorities had the significant lowest retinol intake. Vitamin A intake (expressed in both RE and RAE) showed coincident trends with that of retinol in all stratifications, except for ethnic groups. The highest vitamin A intake level (both RE and RAE) was found in Han, followed by Miao and Buyi, while the lowest level was observed in Man minorities.

\section{Proportion below EAR and above RNI among Chinese adults}

In Chinese DRIs, the estimated average requirement (EAR) and the recommended nutrient intake (RNI) of vitamin $\mathrm{A}$ is set to $560 \mu \mathrm{g} \mathrm{RAE} /$ day and $800 \mu \mathrm{g} \mathrm{RAE} /$ day for males, $480 \mu \mathrm{g} \mathrm{RAE} /$ day and $700 \mu \mathrm{g} \mathrm{RAE} /$ day for females. The proportion of Chinese adults who consumed vitamin A less than EAR, as well as the proportion of adults who consumed vitamin A more than RNI is shown in Table 2. In general, the proportion below EAR was $88.3 \%$ in males and $87.0 \%$ in females; consumption above RNI was only $6.3 \%$ in males and $6.5 \%$ in females. Younger adults seemed to have a healthier vitamin A intake level than older adults, with a lower proportion below EAR and a higher proportion above RNI, whereas no remarkable gender difference in proportions was found for each age group.

\section{Contribution of retinol to total vitamin a intake}

Figure $1 \mathrm{a}$ and $\mathrm{b}$ shows the percentage of daily contribution of retinol to total vitamin A intake (RE and RAE). In terms of RE, retinol accounted for $32.6 \%$ of total vitamin A intake, which contributed $33.5 \%$ in males and $31.8 \%$ in females. $43.6 \%$ of vitamin A intake was attributed to retinol, when expressed in RAE (44.7\% for males and $42.8 \%$ for females). Social-economic differences in the contribution of retinol to total vitamin A were detected. Retinol provided a higher proportion of vitamin A in young, male, urban, eastern, northern, higher education, and higher income groups.

\section{Food sources to the daily vitamin a intake}

Figure 2a shows the percentage contribution of the main food sources to the daily carotene intake in urban and rural adults. Overall, dark vegetables (54.6\%) afforded more than half of carotene intake for the whole population, contributing to a higher percentage for urban groups vs. rural group. Light vegetables (23.6\%) ranked second and fruit (6.0\%) third; tubers contributed 3.8\% and legumes $2.4 \%$. Compared with rural adults, urban adults appeared to consume less carotene from light vegetables and tubers, more from fruit and legumes. All the listed food groups in Fig. 2a afforded more than 95\% to the carotene intake.

Figure $2 \mathrm{~b}$ shows the percentage contribution of the main food sources to the daily carotene intake in east, middle and west areas. Compared with adults in middle and east areas, west adults consumed more carotene from dark vegetables, and less from light vegetables, fruit and tubers.

As shown in Fig. 3a, eggs provided $44.6 \%$ of retinol intake, and were the major contributing food source. Meats and meat products provided $29.2 \%$ and poultry 9.9\% of retinol intake. Finally, fish and milk afforded 6.5 and $4.5 \%$ to retinol intake, respectively. Urban adults seemed to consume more retinol from fish and milk, and less from meats and meat products and poultry than rural adults, with a roughly similar amount from eggs. 


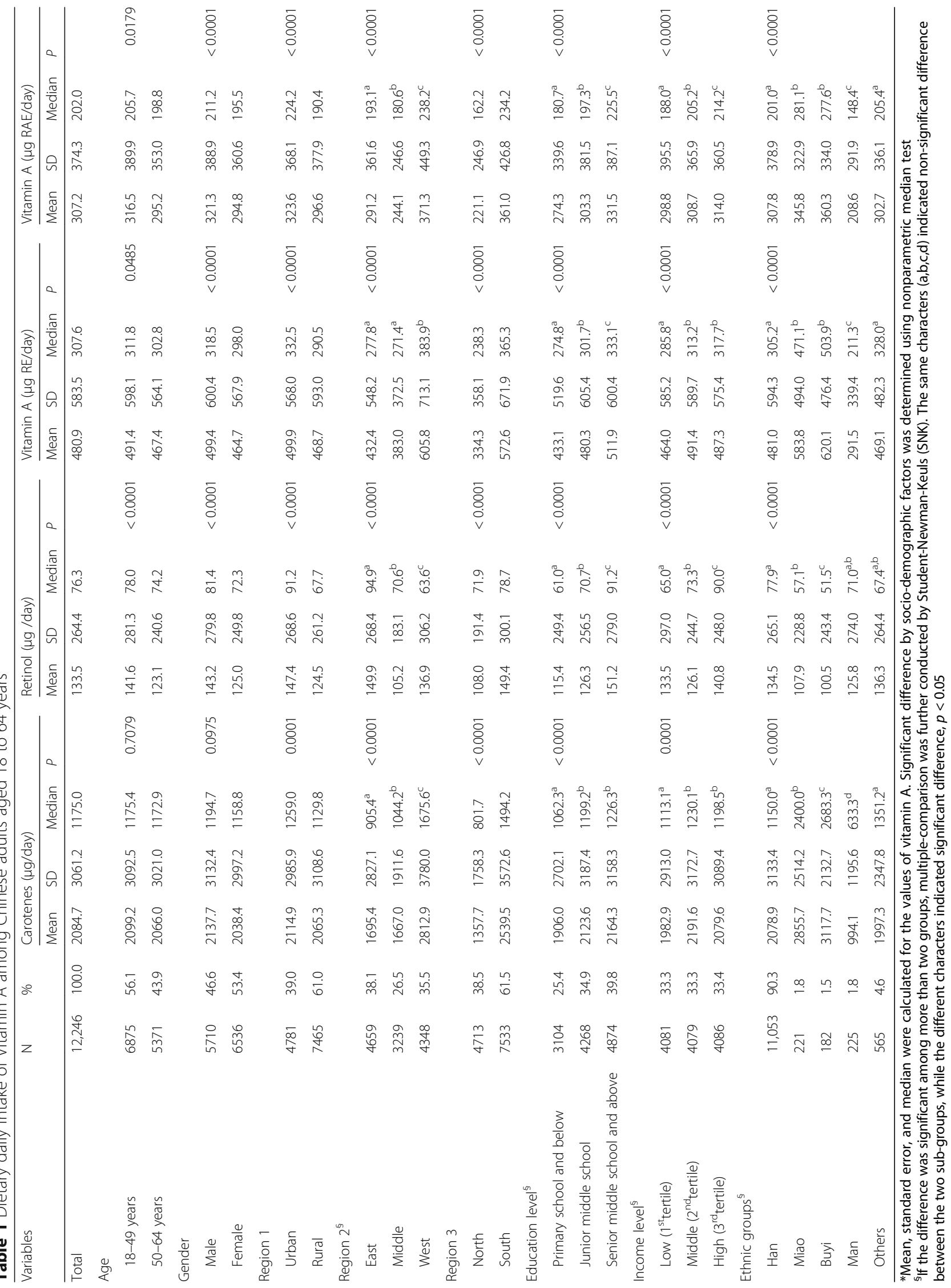


Table 2 Vitamin A intake and proportion below EAR and above RNI among Chinese adults by age and gender

\begin{tabular}{|c|c|c|c|c|c|c|c|c|c|c|c|}
\hline \multirow[t]{2}{*}{ Age } & & \multirow[t]{2}{*}{$\mathrm{N}$} & \multicolumn{2}{|c|}{ Vitamin A ( $\mu \mathrm{g}$ RAE/day) } & \multirow[t]{2}{*}{$P$} & \multicolumn{2}{|c|}{ Below EAR ${ }^{a}$} & \multirow[t]{2}{*}{$P$} & \multicolumn{2}{|c|}{ Above $\mathrm{RNI}^{\mathrm{b}}$} & \multirow[t]{2}{*}{$P$} \\
\hline & & & Mean & Median & & $\mathrm{N}$ & $\%$ & & $\mathrm{~N}$ & $\%$ & \\
\hline \multirow[t]{2}{*}{ 18-49 Years } & Male & 3157 & 330.1 & 214.7 & 0.0008 & 2764 & 87.6 & 0.1744 & 222 & 7.0 & 0.9497 \\
\hline & Female & 3718 & 305.0 & 198.6 & & 3214 & 86.4 & & 260 & 7.0 & \\
\hline \multirow[t]{2}{*}{ 50-64 Years } & Male & 2553 & 310.4 & 207.8 & 0.0003 & 2276 & 89.2 & 0.0946 & 139 & 5.4 & 0.4805 \\
\hline & Female & 2818 & 281.5 & 191.0 & & 2471 & 87.7 & & 166 & 5.9 & \\
\hline \multirow[t]{2}{*}{ Total } & Male & 5710 & 321.3 & 211.2 & $<0.0001$ & 5040 & 88.3 & 0.0313 & 361 & 6.3 & 0.6599 \\
\hline & Female & 6536 & 294.8 & 195.5 & & 5685 & 87.0 & & 426 & 6.5 & \\
\hline
\end{tabular}

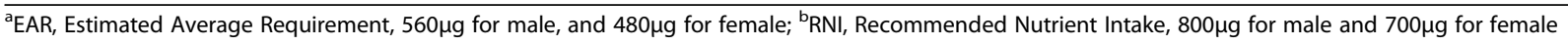

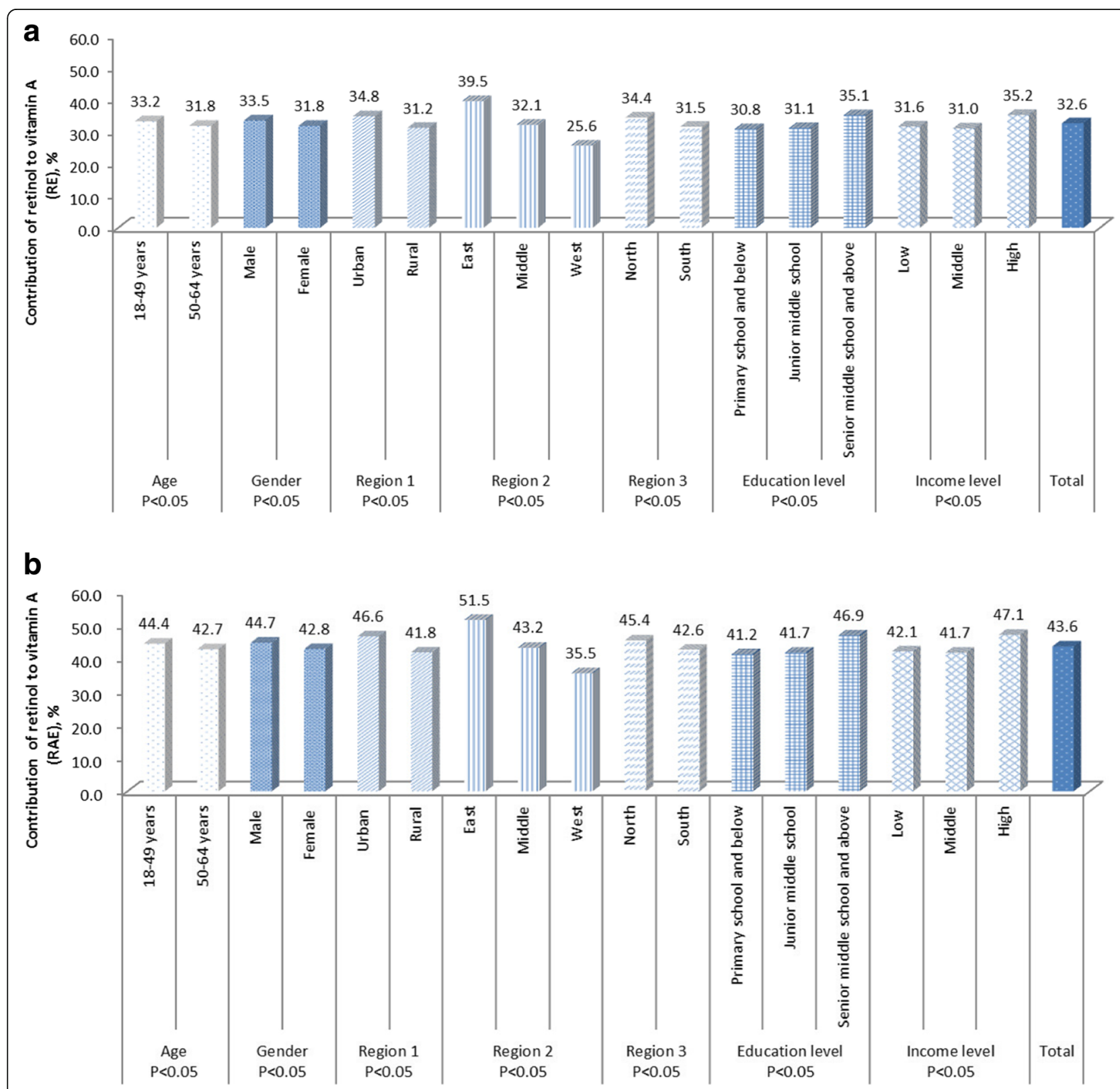

Fig. 1 Contribution of retinol to vitamin A among Chinese adults aged 18 to 64 years: (a) vitamin A expressed as RE; (b) vitamin A expressed as RAE 


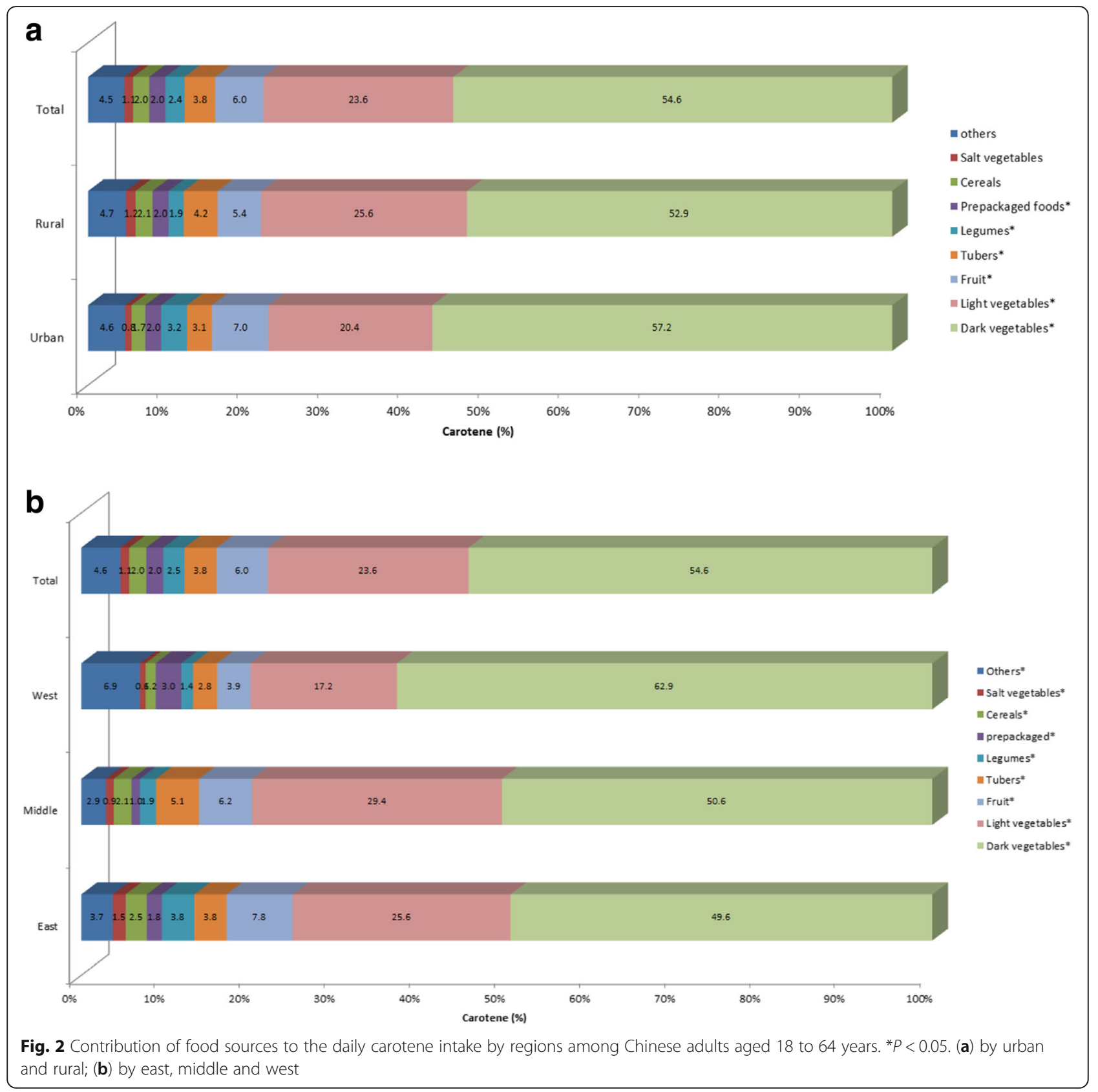

All the food groups in Fig. 3 combined to provide more than $98 \%$ of retinol intake.

Figure $3 \mathrm{~b}$ shows, unlike middle and east areas, meats and meat products were the major contributing food source in west area, providing $39.3 \%$ of retinol intake. Furthermore, west adults seemed to consume more retinol from poultry and animal oil, and less from egg and fish than middle and east adults. Noticeably, fish, milk and prepackaged foods afforded 10.2, 7.3 and $2.5 \%$ to retinol intake in east area, respectively, much higher than that in west and middle area.
Figures 4 and 5 shows that dark vegetables, eggs, light vegetables, meats and meat products, fruit and poultry are the major food sources ofvitamin A intake, contributing nearly $85 \%$ to $\mathrm{RE}$ and RAE for the whole population. Due to different conversion factors of carotene in $\mathrm{RE}$ and RAE calculation formulas, animal source foods contributed a higher proportion to vitamin A intake for RAE than RE. Urban adults consumed more vitamin A from egg and fruit, while less from light vegetables. Adults in west area consumed more vitamin A from dark vegetables, meats and meat products, and less from egg, light vegetables, fruit and fish, than those in middle 


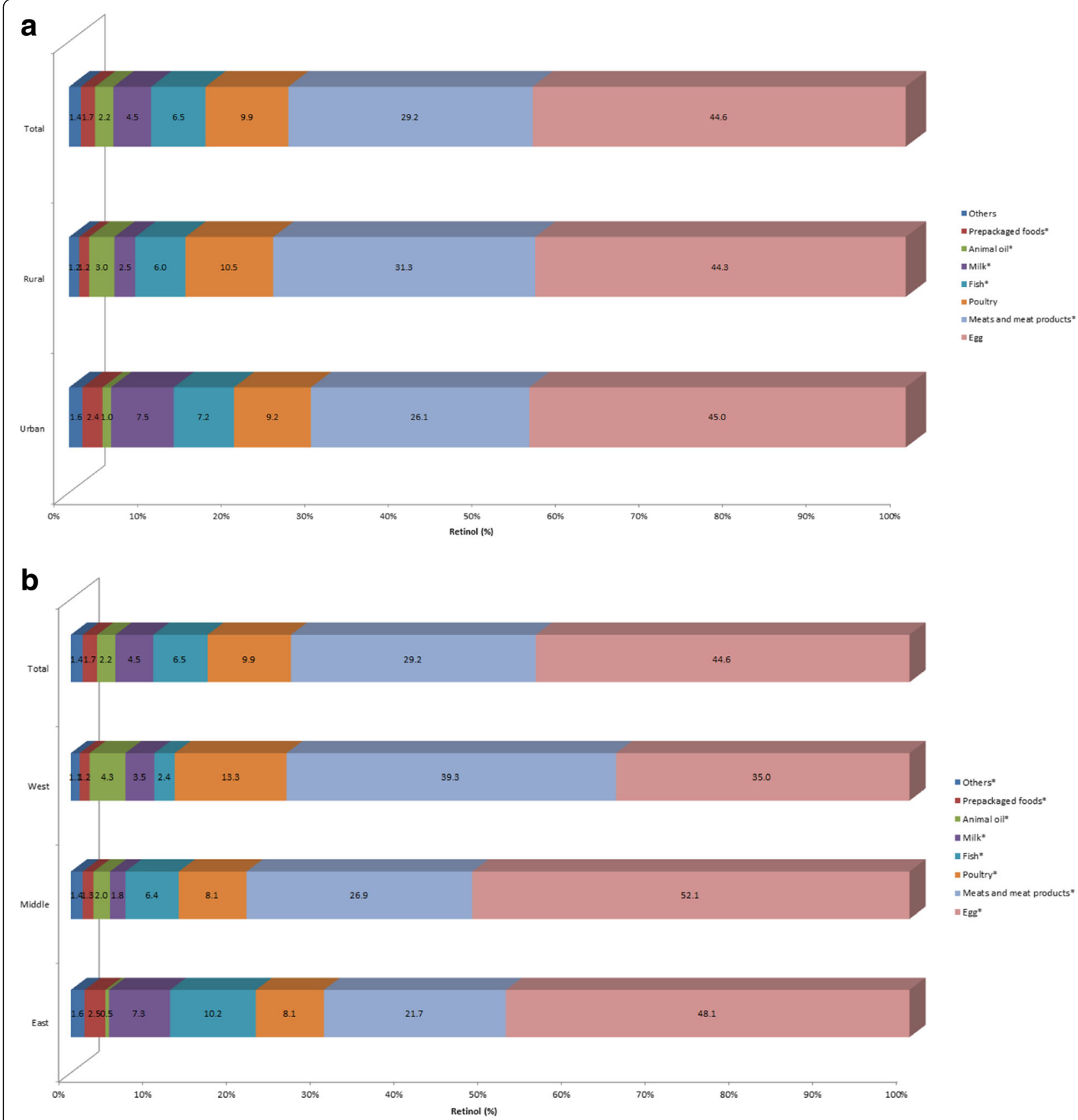

Fig. 3 Contribution of food sources to the daily retinol intake by regions among Chinese adults aged 18 to 64 years. ${ }^{*} P<0.05$. (a) by urban and rural; (b) by east, middle and west

and east areas. Interestingly, fish, milk and prepackaged foods combined to provide $8.8 \%$ of RE and $10.9 \%$ of RAE in east area, which were much higher than that in middle and west areas.

\section{Discussion}

The present article provides a snapshot of dietary intake of vitamin A among Chinese adults. The mean daily intake of vitamin A in this study (480.9 $\mu \mathrm{g} \mathrm{RE} /$ day, and
$307.2 \mu \mathrm{g}$ RAE/day) was roughly in line with the findings from Chinese Nutrition and Health Surveillance (20102012) (441.9 $\mu \mathrm{g} \mathrm{RE} /$ day, and $291.5 \mu \mathrm{g} \mathrm{RAE} /$ day) [16], and that from China National Nutrition and Health Survey $2002(469.2 \mu \mathrm{g} R$ /day) [17]. The above two studies $[16,17]$ using the nationwide data, expressed the vitamin A intake at standard person level $(60 \mathrm{~kg}$ adult men with light physical activity), which may overestimate the intake status. Take this into account, our results indicated 


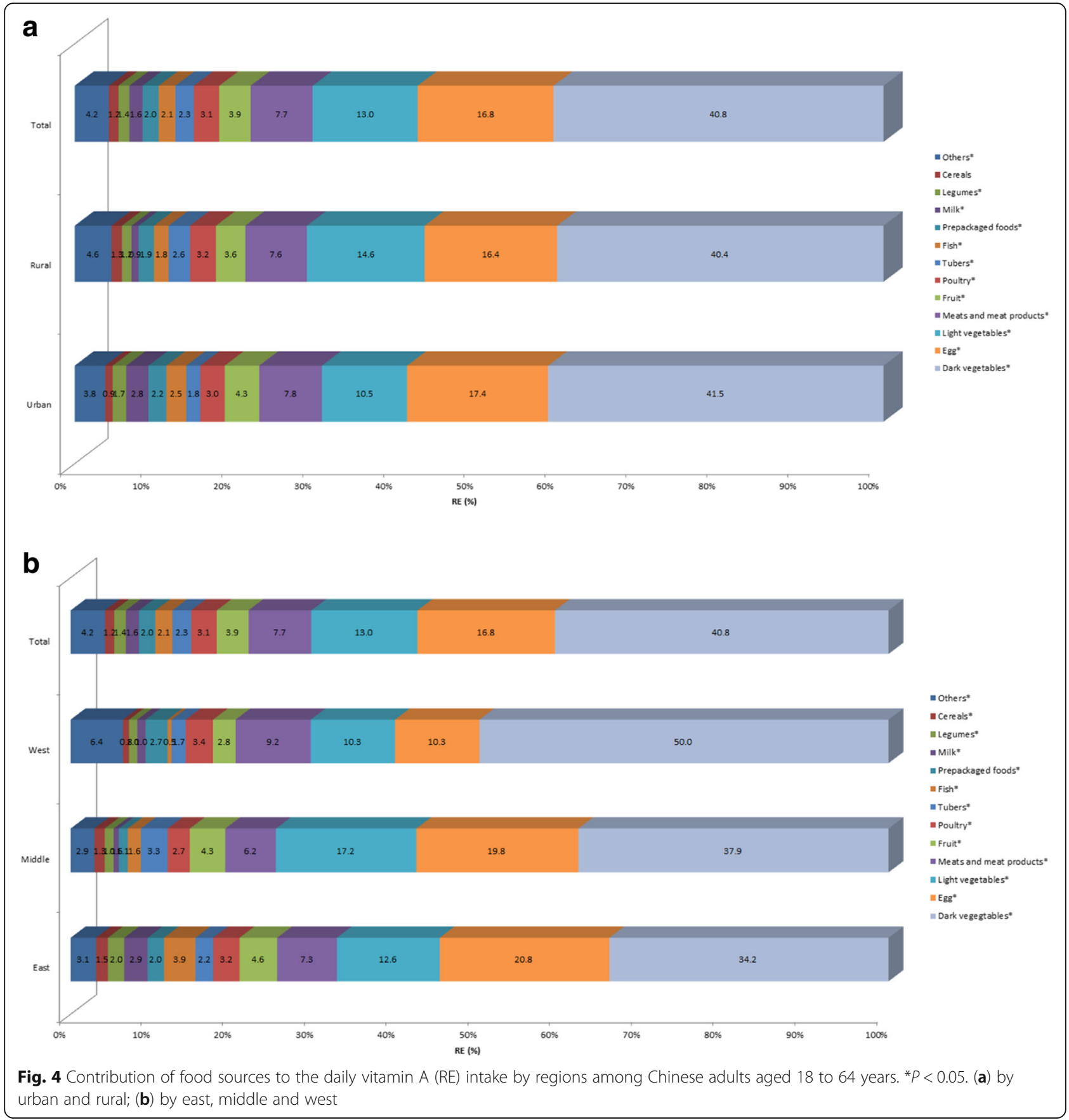

a mild growth of vitamin A intake among Chinese population during the past decade. Studies in other countries [18-22] usually showed vitamin A intake by gender/age groups for which DRIs have been established. Our research found that dietary vitamin A intake of adults in China was lower than that in Korea $(887.8 \mu \mathrm{g} R E /$ day, and $531.84 \mu \mathrm{g}$ RAE/day) [18] and Japan (491 to $571 \mu \mathrm{g}$ $\mathrm{RE} /$ day for men, and 603 to $609 \mu \mathrm{g} \mathrm{RE} /$ day for women) [19], and was much lower than that in other European and American countries, such as Italy $(890 \mu \mathrm{g} R \mathrm{R} /$ day $)$
[20], Spain (716.4 $\mu \mathrm{g}$ RE/day) [6], the United States(656 $\mu \mathrm{g}$ RAE/day for males, and $564 \mu \mathrm{g}$ RAE/day for females) [21], and Mexico (547 $\mu \mathrm{g}$ RAE/day for men, and $536 \mu \mathrm{g}$ RAE/day for women) [22]. When it comes to dietary intake of retinol and carotenes, Chinese adults consumed absolutely less retinol $(133.5 \mu \mathrm{g} /$ day $)$ than those in European countries $(835 \mu \mathrm{g} /$ day $)$, and less carotenes $(2084.7 \mu \mathrm{g} /$ day $)$ than most countries, excluding the Netherlands, Sweden, and Spain [5, 23]. Compared to other Asian countries, such as Japan and Korea, Chinese 


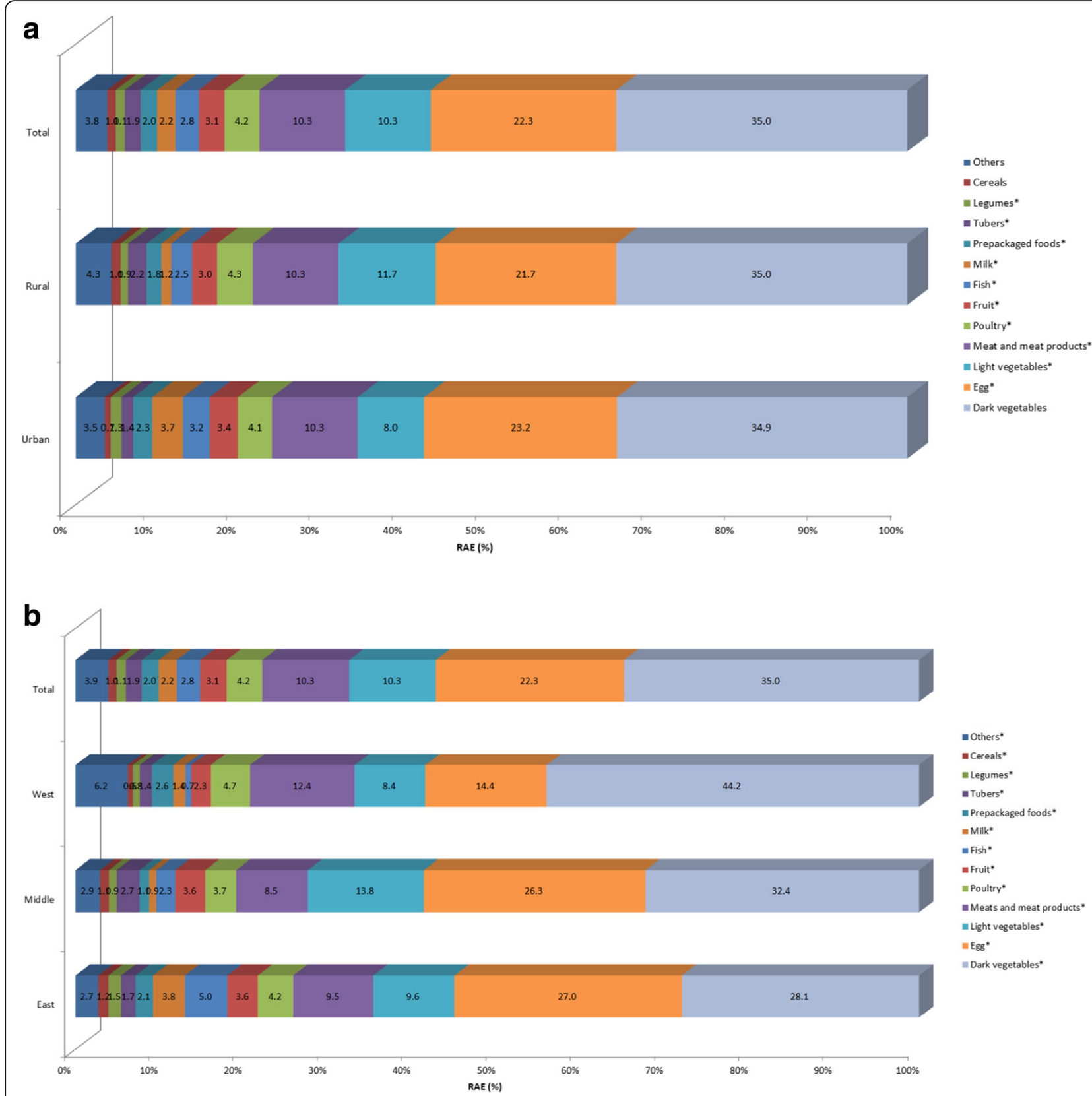

Fig. 5 Contribution of food sources to the daily vitamin A (RAE) intake by regions among Chinese adults aged 18 to 64 years. ${ }^{*} P<0.05$. (a) by urban and rural; (b) by east, middle and west

adults had slightly lower retinol intake and much less carotenes intake $[18,19]$.

Data presented in the current study also shows some very interesting socioeconomic differences in the intake of vitamin A. Higher intake of vitamin A was found in younger, male, urban, western, southern, high education and income groups, and Miao and Buyi minorities. That finding may be explained by the fact that adults in those groups have better access to high quality and balanced foods.
Various countries have released different recommended dietary intake values for vitamin $A$, either as $R E$ or RAE. These different recommendations lead to varying interpretations on the prevalence of inadequate intake. For example, the Korean vitamin A EARs for males and females ( $\geq 20$ years) are 500 to $540 \mu \mathrm{g} R \mathrm{R}$ and 430 to $460 \mu \mathrm{g}$ RE, respectively [24]. The US/Canadian vitamin A EARs are $625 \mu \mathrm{g}$ RAE and $500 \mu \mathrm{g}$ RAE for males and females ( $\geq 20$ years), respectively [1]. The recent Chinese vitamin A EARs are $560 \mu \mathrm{g}$ RAE and $480 \mu \mathrm{g}$ RAE for 
males and females ( $\geq 18$ years), respectively [15]. The reported inadequate proportions below EAR of vitamin A varied from 9.4 to $70.3 \%[18,22,25]$. In our study, $88 \%$ of Chinese adults consumed less vitamin A than EAR, and only $6 \%$ of adults had higher intake than RNI, which meant an inadequate intake at the population level.

Both retinol and carotenes are the main sources of vitamin A intake. In industrialized, Western countries, retinol accounted for nearly $65 \%$ of total vitamin A intake, while carotenes made up only $35 \%$ [14]. Unlike the findings from developed countries, the current study indicated that retinol only accounted for $43.6 \%$ of total vitamin A intake (RAE) in China. The proportion even declined to $32.6 \%$, when vitamin A intake was expressed as RE. The proportion of retinol to total vitamin A intake also showed a significant socio-economic difference. Adults in young, male, urban, eastern, northern, high education, and high income groups consumed more vitamin A from retinol.

Previous reports showed various food sources of vitamin A in different countries. ANIBES Study demonstrated that, among Spanish individuals, milk and products were the main source of retinol (38.7\%), followed by eggs $(22.6 \%)$ and fish (11.4\%); vegetables afforded $52.7 \%$ of carotenes intake, and then fruits ranked second (13.5\%).For total vitamin A intake, vegetables were the main source (31.3\%); milk and products provided 21.7\%; then eggs ranked third (11\%) and fruits fourth (6.9\%) [5]. EPIC Study showed that European adults obtained their retinol mainly from meats and meat products (51.7\%); added fats and dairy products took the second and third place (18.5 and $15.6 \%$, respectively); vegetables and fruit provided 67.8 and $7.8 \%$ of $\beta$-carotene intake [23].

Unlike the Western diet [26], dark vegetables and light vegetables were the major contributors of carotene in China (54.6 and $23.6 \%$, respectively), followed by fruit (6.0\%) and tubers (3.8\%); egg provided $44.6 \%$ of retinol; meat and products afforded $29.2 \%$; followed by poultry (9.9\%) and fish (6.5\%); milk only provided $4.5 \%$. The current study also showed that when vitamin A was expressed as RE the order of the major contributors to vitamin A intake was dark vegetables, eggs, light vegetables, meats and meat products, fruit, poultry, tubers and fish; the order changed slightly when vitamin A was expressed as RAE, with animal source foods contributing more vitamin A and plant source foods less.

China has undergone dramatic socioeconomic changes in the past decades, as well as changes in food consumption and eating behaviors [27]. Although the consumption of animal source foods increased greatly during the past years [28], Chinese adults obtained vitamin A mainly from plant source foods.
It should be noted that there are some limitations in our study. First, vitamin A intake from supplements was not included in the analysis because of insufficient data of supplement use in CNTCS. However, unlike the common use of dietary supplements in the Western world $[29,30]$, supplement use was far lower in China [31], which leads to little bias of the results. Second, specific carotenes components, such as $\alpha$-carotene, $\beta$-carotene, and $\beta$-cryptoxanthin, were not distinguished in the China food composition table and thus went beyond the scope of this paper.

Other study showed that adequate dairy intake greatly improved vitamin A intake, especially among women and older adults [25]. Meanwhile, in the recent Chinese Dietary Guidance (2016) [32], the Chinese Nutrition Society encourages people to consume plenty of vegetables, milk and soybeans, as well as an appropriate amount of fish, poultry, eggs and lean meant.

\section{Conclusions}

The present study highlights that, according to the current recommended values, there was a substantial percentage of Chinese adults who had low intakes of vitamin A. Compared with adults in developed countries, the intake of vitamin A, especially retinol intake, was much lower among Chinese adults. The findings illustrate the public health actions are needed to tackle the inadequate intake of vitamin A in China.

\section{Abbreviations}

CHNS: China Health and Nutrition Survey; CNTCS: China Nutritional Transition Cohort Study; DRIs: Dietary Reference Intakes; EAR: Estimated Average Requirement; RAE: Retinol Activity Equivalents; RE: Retinol Equivalents; RNI: Recommended Nutrient Intake

\section{Funding}

The "China Nutritional Transition Cohort Study" project received funding from Ministry of Finance of the People's Republic of China (NO. 13103110700015005). The present study is also sponsored by Carolina Population Center (P2C HD050924, T32 HD007168), the University of North Carolina at Chapel Hill, the NIH (R01-HD30880, DK056350, R24 HD050924, and R01-HD38700) and the NIH Fogarty International Center (D43 TW009077, D43 TW007709) for financial support for the CHNS data collection and analysis files from 1989 to 2011 and future surveys.

\section{Availability of data and materials}

The datasets supporting the conclusions of this article are available in http:// www.cpc.unc.edu/projects/china.

\section{Authors' contributions}

WWD analyzed and interpreted the data, and drafted the manuscript; HJW and ZHW contributed to data analysis; JGZ and CS contributed to statistical analysis and data interpretations; XFJ, JZ, HRJ, FFH, YYOY, YW and LL contributed to data interpretation; BZ supervised the study design, analysis and interpretation. All authors provided critical comments on the manuscript, read and approved the final manuscript.

\section{Ethics approval and consent to participate}

The CNTCS protocol was approved by ethics committee of National Institute for Nutrition and Health, Chinese Center for Disease Control and Prevention. All participants gave their written informed consent before they participated in the study. 


\section{Consent for publication}

Not applicable.

\section{Competing interests}

The authors declare that they have no competing interests.

\section{Publisher's Note}

Springer Nature remains neutral with regard to jurisdictional claims in published maps and institutional affiliations.

Received: 30 January 2018 Accepted: 6 June 2018 Published online: 11 June 2018

\section{References}

1. Panel on Micronutrients, Subcommittees on Upper Reference Levels of Nutrients and of Interpretation and Use of Dietary Reference Intakes, and the Standing Committee on the Scientific Evaluation of Dietary Reference Intakes. Dietary Reference Intakes for Vitamin A, Vitamin K, Arsenic, Boron, Chromium, Copper, lodine, Iron, Manganese, Molybdenum, Nickel, Silicon, Vanadium, and Zinc. National Academy Press: Washington, D.C., the United States of America. 2001; p.82-146.

2. Stevens GA, Bennett JE, Hennocq Q, Lu Y, De-Reqil LM, Rogers L, Danaei G, Li G, White RA, Flaxman SR, Oehrle SP, Finucane MM, Guerrero R, Bhutta ZA, Then-Paulino A, Fawzi W, Black RE, Ezzati M. Trends and mortality effects of vitamin a deficiency in children in 138 low-income and middle-income countries between 1991 and 2013: a pooled analysis of population-based surveys. Lancet Glob Health. 2015;3(9):e528-36.

3. Yang C, Chen J, Liu Z, Yun C, Piao J, Yang X. Prevalence and influence factors of vitamin a deficiency of Chinese pregnant women. Nutr J. 2016;15:12.

4. Yang C, Chen J, Guo N, Liu Z, Yun C, Li Y, Piao J, Yang X. Comparison on the status of vitamin a in 6- to 13-year-old children between 2002 and 2012 in China. Nutr J. 2016;15(1):50.

5. Olza J, Aranceta-Bartrina J, Gonzalez-Gross M, Ortega RM, Serra-Majem L, Verela-Moreiras G, Gil A. Reported dietary intake and food sources of zinc, selenium, and vitamins a, E and C in the Spanish population: findings from the ANIBES study. Nutrients. 2017;9(7):E697.

6. Beltran-de-Miguel B, Estevez-Santiago R. Olmedilla-AlonsoB. Assessment of dietary vitamin a intake (retinol, alpha-carotene, beta-carotene, betacryptoxanthin) and its sources in the National Survey of dietary intake in Spain (2009-2010). Int J Food Sci Nutr. 2015;66(6):706-12.

7. FAO/WHO Joint Expert Consultation. Requirements of vitamin A, iron, folate and vitamin B12. In: FAO. FAO Food and Nutrition Series. Rome; 1988. No.23.

8. Trumbo P, Yates AA, Schlicker S, Poos M. Dietary reference intakes: vitamin a, vitamin $\mathrm{K}$, arsenic, boron, chromium, copper, iodine, iron, manganese, molybdenum, nickel, silicon, vanadium, and zinc. J Am Diet Assoc. 2001; 101(3):294-301.

9. National Health and Medical Research Council, Australian Government Department of Health and Ageing, New Zealand Ministry of Health. Nutrient reference values for australia and new Zealand. 1.2 version. Canberra: National Health and Medical Research Council; 2006.

10. Cheng Y. The introduction fo Chinese dietary reference intakes 2013. Acta Nutriments Sinica. 2014;36(4):313-7.

11. Popkin BM, Du S, Zhai F, Zhang B. Cohort profile: the China health and nutrition survey-monitoring and understanding socio-economic and health change in China, 1989-2011. Int J Epidemiol. 2010;39(6):1435-40.

12. Zhang B, Zhai F, Du SF, Popkin BM. The China health and nutrition survey, 1989-2011. Obes Rev. 2014;15(Suppl 1):2-7.

13. Yang YX, Wang GY, Pan XC. China Food Composition, 2nd ed.;Peking University Medical Press: Beijing, China, 2009, ISBN: 9787811167276.

14. Weber D. GruneT. The contribution of beta-carotene to vitamin a supply of humans. Mol Nutr Food Res. 2012;56(2):251-8.

15. Chinese Nutrition Society. Chinese DRIs handbook. Beijing: Standards Press of China; 2014

16. He YN, Wang Z, Zhao LY, Fang YH, Yang XG, Zhao WH. Dietary intake of vitamins in Chinese population from 2010 to 2012. Acta Nutrimenta Sinica. 2017;39(02):112-5

17. Li Y, Zhai FY, He YN, Yu DM, Wang ZH, Zhao LY, Yu WT. Survey on the status of dietary vitamin a intakes in Chinese residents. Wei Sheng Yan Jiu. 2007;36(2): 200-2.

18. Kim S, Kim YN, Cho YO. Vitamin a status of 20- to 59-year-old adults living in Seoul and the metropolitan area. Korea Nutr Res Pract. 2012;6(1):45-50.
19. Kato $Y$, Ikehara S, Maruyama K, Inagawa M, Oshima M, Yokota K, Yamazaki T, Kishi M, Murai S, Umesawa M, Ma E, Yamagishi K, TanigawaT KM, Sato S, Shimamoto $\mathrm{T}$, Iso $\mathrm{H}$. Trends in dietary intakes of vitamins $\mathrm{A}, \mathrm{C}$ and $\mathrm{E}$ among Japanese men and women from 1974 to 2001. Public Health Nutr. 2009; 12(9):1343-50

20. Sette S, Le Donne C, Piccinelli R, Arcella D, Turrini A, Leclercq C, INRAN-SCAI 2005-6 Study Group. The third Italian National Food Consumption Survey, INRAN-SCAI 2005-06-part 1: nutrient intakes in Italy. Nutr Metab Cardiovasc Dis. 2011:21(12):922-32.

21. Moshfegh A, Goldman J, Cleveland L. What we eat in America, NHANES 2001-2002: usual nutrient intakes from food compared to dietary reference intakes. U.S. Department of Agriculture; 2005.

22. Pedroza-Tobias A, Hernández-Barrera L, López-Olmedo N, García-Guerra A Rodríguez-Ramírez S, Ramírez-Silva I, Villalpando S, Carriquiry A, Rivera JA. Usual vitamin intakes by Mexican populations. J Nutr. 2016;146(9):1866S-73S.

23. Jenab M, Salvini S, van Gils CH, Brustad M, Shakya-Shrestha S, Buijsse B,

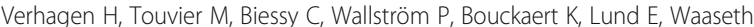
M, Roswall N, Joensen AM, Linseisen J, Boeing H, Vasilopoulou E, Dilis V, Sieri S, Sacerdote C, Ferrari P, Manjer J, Nilsson S, Welch AA, Travis R, Boutron-Ruault MC, Niravong M, Bueno-de-Mesquita HB, van der Schouw YT, Tormo MJ, Barricarte A, Riboli E, Bingham S, Slimani N. Dietary intakes of retinol, beta-carotene, vitamin D and vitamin $\mathrm{E}$ in the European Prospective Investigation into Cancer and Nutrition cohort. Eur J Clin Nutr. 2009; 63(Suppl 4):S150-78.

24. The Korean Nutrition Society. Dietary reference intakes for Koreans. Seoul: Kookjin Publishing Co; 2010.

25. Quann EE, Fulgoni VL 3rd, Auestad N. Consuming the daily recommended amounts of dairy products would reduce the prevalence of inadequate micronutrient intakes in the United States: diet modeling study based on NHANES 2007-2010. Nutr J. 2015;14:90.

26. Goldbohm RA, Brants HA, Hulshof KF, van den Brandt PA. The contribution of various foods to intake of vitamin a and carotenoids in the Netherlands. Int J Vitam Nutr Res. 1998:68(6):378-83.

27. Popkin BM. Synthesis and implications: China's nutrition transition in the context of changes across other low- and middle-income countries. Obes Rev. 2014;15(Suppl 1):60-7.

28. Zhai FY, Du SF, Wang ZH, Zhang JG, Du WW, Popkin BM. Dynamics of the Chinese diet and the role of urbanicity, 1991-2011. Obes Rev. 2014;15(Suppl 1): 16-26.

29. Beitz R, Mensink GB, Fischer B, Thamm M. Vitamins-dietary intake and intake from dietary supplements in Germany. Eur J Clin Nutr. 2002;56(6): 539-45.

30. Swan G. Findings from the latest National Diet and nutrition survey. Proc Nutr Soc. 2004:63(4):505-12.

31. He Y, Yang Z, Xu J, Sha YM, Ren ZY, Pang XH, Wang HJ, Zhai FY. Dietary supplement use in Beijing. Wei Sheng Yan Jiu. 2008:37(1):75-8.

32. Wang SS, Lay S, Yu HN, Shen SR. Dietary guidelines for Chinese residents (2016): comments and comparisons. J Zhejiang Univ Sci B. 2016;17(9):649-56.

\section{Ready to submit your research? Choose BMC and benefit from:}

- fast, convenient online submission

- thorough peer review by experienced researchers in your field

- rapid publication on acceptance

- support for research data, including large and complex data types

- gold Open Access which fosters wider collaboration and increased citations

- maximum visibility for your research: over $100 \mathrm{M}$ website views per year

\section{At BMC, research is always in progress.}

Learn more biomedcentral.com/submissions 